\title{
The relationship between sensory impairment and functional independence among elderly Parminder Raina ${ }^{* 1}$, Micheline Wong ${ }^{2}$ and Helen Massfeller ${ }^{1}$
}

\begin{abstract}
Address: ${ }^{1}$ Department of Clinical Epidemiology and Biostatistics, Faculty of Health Sciences, McMaster University, Hamilton, Canada and ${ }^{2}$ Centre for Community Health and Health Evaluation Research, British Columbia Research Institute for Children's and Women's Health, \& Department of Health Care \& Epidemiology, University of British Columbia, Vancouver, Canada

Email: Parminder Raina* - praina@mcmaster.ca; Micheline Wong - michelinewong@hotmail.com; Helen Massfeller - massfeh@mcmaster.ca

* Corresponding author
\end{abstract}

Published: 07 May 2004

BMC Geriatrics 2004, 4:3
Received: 25 September 2003

Accepted: 07 May 2004

This article is available from: http://www.biomedcentral.com/I47|-23/8/4/3

(C) 2004 Raina et al; licensee BioMed Central Ltd. This is an Open Access article: verbatim copying and redistribution of this article are permitted in all media for any purpose, provided this notice is preserved along with the article's original URL.

\begin{abstract}
Background: It has been well established that increasing age is associated with decreasing functional ability in older adults. It is important to understand the specific factors that affect instrumental activities of daily living (IADL) and functional independence among older adults with sensory disabilities.
\end{abstract}

Methods: Nationally representative sample of adults aged 55 years and older with seeing or hearing disabilities were categorised into three sensory classifications: "Seeing Disabled but Hearing Abled" (SD-HA), "Hearing Disabled but Seeing Abled" (HD-SA), and both "Seeing and Hearing Disabled" (SD-HD). The additional category of "Seeing Disabled and/or Hearing Disabled" (SD and/ or HD) was created to calculate the total of all individuals from the above categories who either had a seeing or hearing disability or both sensory disabilities. Respondents were asked to indicate whether they received assistance in performing seven IADL and their level of functional independence.

Results: The most common factors that affect IADL were heavy chores, grocery shopping and housework. Individuals with both seeing and hearing disabilities (SD-HD) reported having the most IADL restrictions, followed by individuals with only seeing disabilities (SD-HA) and only hearing disabilities (HD-SA). Individuals with severe sensory disabilities were generally more likely to report IADL restrictions and less likely to have decision-making control and be happy with their lives. In each sensory classification, females aged 55-64 years and 65 years and older reported more IADL restrictions than males.

Conclusion: Both seeing and hearing disabilities have a significant impact on restricting an individual's IADL.

\section{Background}

Sensory disabilities dramatically increase with age and may seriously compromise an older person's ability to carry out routine daily activities. In 1991, visual and hearing impairments were reported by over $10 \%$ and $17 \%$ of persons aged 65 years and over, respectively [1]. Given the projected growth of the older adult population, it is particularly important to continue understanding the relationship between visual and hearing impairment and functional independence. Few studies have elaborated on 
the specific types of daily restrictions experienced by older adults, nor have they looked at the association between decrements of sensory severity and functional outcomes. The purpose of this study was to determine the association between self-reported sensory disabilities and specific IADL restrictions among adults aged 55 years and older. The study also examined the relationship between severity of sensory disabilities and functional independence.

\section{Methods}

\section{Survey design}

The 1991 Health and Activities Limitation Survey (HALS) is a cross-sectional survey on a nationally representative sample of Canadians 15 years and older selected from the 1991 Canadian Census. A sample of persons with disabilities was identified consisting of two groups: 1) Those individuals who identified themselves on the Census Long Form as having either a physical or mental disability and 2) those who originally indicated on the Census Long Form that they did not have a physical or mental disability but were later reclassified as disabled when they completed the HALS screening questions [2]. More in-depth details of the sampling procedure are described elsewhere [3].

The overall sample size for the 1991 survey was 91,355 with a total response rate of $92 \%$. The current study focused on non-institutionalized adults aged 55 years and older who identified themselves on the Census Long Form as having either a physical or mental disability. The unweighted (and weighted) sample sizes for the respondents aged 55-64 years old were 11,507 $(2,365,000)$ and $5,106(2,906,900)$ for those aged 65 years and older (herein, seniors). Due to the relatively small sample size for seniors in the 1991 HALS, further age breakdowns were not available from Statistics Canada.

Respondents with a disability completed the HALS through a face-to-face interview with an experienced interviewer from Statistics Canada. If the individual's physical or psychological disability prevented him or her from responding to the survey questions, an interview was conducted with another member of the household. Thus, approximately $12 \%$ of all cases were completed by proxy.

\section{Variables}

\section{Disability status}

Respondents were asked about their ability to do certain activities (i.e., bladder and bowel control, toilet use, grooming, bathing, dressing, feeding, and transfer) even when using a special aid, such as glasses or a hearing aid [2]. Only restrictions that were expected to last six months or more and were not eliminated by the use of an assistive device were sought. Those who indicated that they had at least one seeing-related Activities of Daily Living (ADL) restriction were classified as having a seeing disability. Those who indicated that they had at least one hearingrelated ADL restriction were classified as having a hearing disability. The ADL questions used to assess a hearing disability asked about the ability of the respondent to do certain activities even when using an assistive device.

Respondents who reported having seeing or hearing disabilities were further categorised into three sensory classifications: "Seeing Disabled but Hearing Abled" (SD-HA), "Hearing Disabled but Seeing Abled" (HD-SA), and both "Seeing and Hearing Disabled" (SD-HD). The additional category of "Seeing Disabled and/or Hearing Disabled" (SD and/or HD) was created to calculate the total of all individuals from the above categories who either had a seeing or hearing disability or both sensory disabilities.

\section{Severity of disability}

Severity indexes were developed to assess the degree of disability for respondents. The indexes were formed based on the formulation used by HALS in the development of an overall severity index $[2,4]$. A seeing severity index was developed based on the number of seeing ADL restrictions respondents had and the degree to which these restrictions interfered with vision. The seeing severity index comprised of two ADL restriction items (Table 1). Respondents who scored a total of 1 point on the seeing severity index were classified as having a "mild" seeing disability. Those who scored 2 points had a "moderate" seeing disability, and those who scored 3 or 4 points were considered "severe".

The hearing severity index was developed from the number of hearing ADL restrictions respondents had and the degree to which these restrictions interfered with hearing. The hearing severity index had two ADL restriction questions, and a question asking respondents whether they were able to hear what was said over a normal telephone even if a hearing aid was used (Table 1). Respondents who scored a total of 1 point were classified as having a "mild" hearing disability, 2 points as "moderate" hearing disability, and 3 to 5 points as "severe" hearing disability.

A sensory disability severity index was developed by adding together the total scores of the seeing and hearing severity indexes. For respondents classified as SD or HD, 1 point was classified as a "mild" sensory disability, 2 points as a "moderate" sensory disability, and 3 to 9 points as a "severe" sensory disability. Because respondents with both a seeing and hearing disability could not have a score lower than 2 on the sensory disability severity index, those who scored 2 points were classified with a "mild" sensory disability, 3 points as "moderate" sensory 
Table I: Activity of Daily Living Items Used to Derive Seeing, Hearing and Total Severity Indexes, Health Activity Limitation Survey, 1991

\begin{tabular}{lll}
\hline \multicolumn{1}{c}{ ADL Item } & Score on Seeing Severity Index & Score on Hearing Severity Index \\
\hline $\begin{array}{l}\text { Difficulty seeing ordinary newsprint with glasses or } \\
\text { contact lenses if usually worn? }\end{array}$ & $\begin{array}{l}\text { No }=0 \text { Yes, but able }=\text { I Yes but, } \\
\text { completely unable }=2 \\
\text { Dofficulty clearly seeing the face of someone across a } \\
\text { room with glasses or contact lenses if usually worn? } \\
\text { completely unable }=2\end{array}$ & \\
$\begin{array}{l}\text { Difficulty hearing what is said in a conversation with one } \\
\text { person? }\end{array}$ & & $\begin{array}{l}\text { No }=0 \text { Yes, but able }=\text { I Yes but, } \\
\text { completely unable }=2\end{array}$ \\
$\begin{array}{l}\text { Difficulty hearing what is said in a group conversation } \\
\text { with at least three other people? }\end{array}$ & $\begin{array}{l}\text { No }=0 \text { Yes, but able }=\text { I Yes but, } \\
\text { completely unable }=2 \\
\text { Able to hear what is said over the telephone? }\end{array}$ & \begin{tabular}{l} 
Yes $=0$ No $=1$ \\
\hline
\end{tabular}
\end{tabular}

disability, and 4 to 9 points as a "severe" sensory disability.

\section{Restrictions in Instrumental Activities of Daily Living (IADL)}

Disabled respondents were asked to indicate whether they received assistance in performing seven IADL, namely meal preparation, shopping, household chores, heavy chores, personal finances, personal care, and moving around their residence. Only respondents who indicated that they received assistance because of their disability were classified as IADL restricted. An additional variable, "any activity", was created to identify the proportion of respondents reporting at least one IADL restriction.

\section{Functional independence}

Three measures were used to define functional independence, IADL restrictions, emotional well-being and perceived level of control over decision-making in everyday situations. To measure emotional well-being, respondents were asked, "Overall, how would you say things are these days?" The possible responses were 'very happy', 'pretty happy', and 'not happy' as possible responses [2]. Respondents who responded either "very happy" or "pretty happy were classified as happy. Those who responded "not happy" were classified as unhappy. To measure perceived decision-making control, respondents were asked, "How much control do you feel you have in making decisions that affect your everyday activities?" The possible responses were 'I make all the decisions', 'I make most of the decisions', 'I do not make very many decisions', or 'I make no decisions.' Respondents who indicated that they made all or most decisions were classified as having decision-making control. Those who indicated they did not make many decisions or any decision at all were classified as having no decision-making control.

\section{Statistical analyses}

Relationship between sensory disabilities and IADL restrictions

IADL restrictions were examined by age, sex and sensory disability classifications (SD-HA, HD-SA, SD-HD, and SD and/or HD). For each classification, logistic regression analyses were conducted to compare the odds of IADL restrictions between respondents with a particular sensory disability and all other persons in HALS who were classified as being disabled (i.e. individuals in the other sensory disability classifications, as well as individuals with speaking, mobility and agility disabilities). Odds ratios were adjusted for marital status, type of dwelling, degree of urbanisation, and total household income. These factors have been consistently found in the literature to be associated with the presence of sensory disabilities and chronic conditions among older adults $[3,5,6]$. Other factors adjusted for included whether or not respondents used any physical aids to overcome their disabilities (e.g. aids used to overcome sensory and other speaking, mobility and agility disabilities), modified their residence in any way to help deal with their disability, and reported any other disabilities.

Due to the multi-staged, stratified sampling strategy used in HALS, a weighting process was used for all analyses so that prevalence estimates could correctly reflect the Canadian population. Every respondent was assigned a weight corresponding to the number of people each respondent would represent based on the Canadian Census. These weights were used to generate all population estimates. Although this weighting procedure generates accurate estimates, significance tests and confidence intervals were inflated and resulted in greater Type I error. Therefore, for all inferential analysis using weighted data, such as logistic regression, weights were rescaled by dividing the weight for each respondent by the average weight of all 
Table 2: Population Characteristics and Proportion of Sensory Disabled Canadian Older Adults Aged 55 Years and Older, 1991 Health and Activities Limitation Survey $(n=5,271,900) *$

\begin{tabular}{|c|c|c|c|}
\hline Variables & & Overall Sample (\%) & Sensory Disabled (\%) \\
\hline \multirow[t]{2}{*}{ Age } & 55-64 Years & 44.9 & $10.5 \S$ \\
\hline & $65+$ Years & 55.1 & 23.0 \\
\hline \multirow[t]{2}{*}{ Gender } & Female & 54.4 & $18.3 \ddagger$ \\
\hline & Male & 45.6 & 16.6 \\
\hline \multirow[t]{3}{*}{ Marital Status } & Single & 7.7 & $19.2 \S$ \\
\hline & Married & 65.1 & 15.6 \\
\hline & Div/Sep/Wid & 27.1 & 21.3 \\
\hline \multirow[t]{4}{*}{ Total Household Income } & Income less than 10,000 & 19.6 & $19.5 \S$ \\
\hline & $\$ 10,000-\$ 24,999$ & 50.0 & 20.0 \\
\hline & $\$ 25,000-\$ 34,999$ & 30.4 & II.I \\
\hline & $\$ 35,000$ and over & 17.0 & 11.5 \\
\hline \multirow[t]{2}{*}{ Tenure of Dwelling } & Owned & 75.1 & $16.4 \S$ \\
\hline & Rented & 22.3 & 20.4 \\
\hline \multirow[t]{2}{*}{ Type of Dwelling } & Single & 64.2 & $17.9+$ \\
\hline & Other & 35.8 & 16.6 \\
\hline \multirow[t]{3}{*}{ Number of Persons in Household } & I person & 19.6 & $22.6 \S$ \\
\hline & 2 persons & 50.0 & 16.8 \\
\hline & 3 persons & 30.4 & 15.0 \\
\hline \multirow[t]{2}{*}{ Degree of Urbanization } & Urban & 80.2 & $16.6 \S$ \\
\hline & Rural & 19.8 & 20.8 \\
\hline \multirow[t]{6}{*}{ Regions of Canada } & Atlantic & 8.3 & $20.8 \S$ \\
\hline & Quebec & 25.3 & $12.9^{\circ}$ \\
\hline & Ontario & 37.9 & 17.6 \\
\hline & Prairies & 15.5 & 21.5 \\
\hline & British Columbia & 12.8 & 18.8 \\
\hline & Yukon and NWT & 0.1 & 20.0 \\
\hline \multirow[t]{4}{*}{ Sensory Disability Classification } & SD-HA & 4.1 & - \\
\hline & HD-SA & 10.5 & - \\
\hline & SD-HD & 3.0 & - \\
\hline & SD and/or HD (Total) & 17.6 & - \\
\hline
\end{tabular}

$*_{n}=$ Weighted sample size of respondents Chi-square analyses were conducted separately for each response category to compare individuals with and without sensory disabilities $\dagger p \leq 0.05, \ddagger p<0.01, \S p<0.001$

respondents to produce more accurate significant tests and confidence intervals [2].

Relationship between severity of sensory disabilities and functional independence

To examine the association between severity of seeing disability and functional independence, three separate logistic regressions analyses were run between the severity indices in each sensory disability classification and each of the measures of functional independence. These regression analyses were adjusted for the same variables as the regression analyses on IADL restriction.

\section{Results}

\section{Characteristics of older adults}

Population characteristics and the proportion of Canadian older adults aged 55 years and older with sensory disabilities are presented in Table 2. Ten percent of respondents aged 55-64 years old, and 23\% of all seniors reported at least one sensory disability. Hearing disabilities were the most commonly reported among older adults $(13.5 \%)$ followed by seeing disabilities $(7.1 \%)$. Approximately $3.0 \%$ of individuals had both seeing and hearing disabilities. Females reported more sensory disabilities than males $(\mathrm{p}<0.01)$. As well, about $20 \%$ of individuals with incomes of less than $\$ 25,000$, compared with about $11 \%$ of those with incomes of $\$ 25,000$ or more, reported more seeing or hearing disabilities ( $\mathrm{p}<$ $0.001)$.

Relationship between disabilities and restrictions in IADL The relationships between IADL restrictions and each sensory disability classification are presented in Tables 3 to 6 . Overall, both females and males aged 65 years and older with at least one seeing or hearing disability (SD and/or HD) reported having more IADL restrictions in "any activity" compared to their younger counterparts. Females with a SD and/or HD generally reported more restrictions in 
Table 3: Associations Between Sensory Disabilities and Assistance Needed with Instrumental Activities of Daily Living (IADL) Among Disabled Females 55-64 Years, 199 I Health and Activity Limitation Survey $(n=285,632) *$

\begin{tabular}{|c|c|c|c|c|c|c|c|c|}
\hline \multirow[t]{2}{*}{ IADL Restriction** } & \multicolumn{2}{|c|}{ SD and/or HD (Total) } & \multicolumn{2}{|c|}{ SD-HD } & \multicolumn{2}{|c|}{ SD-HA } & \multicolumn{2}{|c|}{ HD-SA } \\
\hline & $\%$ & Adj OR† $(95 \% \mathrm{Cl})$ & $\%$ & Adj OR† $(95 \% \mathrm{Cl})$ & $\%$ & Adj OR† $(95 \% \mathrm{Cl})$ & $\%$ & Adj ORt $(95 \% \mathrm{Cl})$ \\
\hline Any Activity & 54.1 & $0.89(0.72-1.08)$ & 74.2 & $1.68(0.93-3.03)$ & 60.8 & $\mathrm{I} .00(0.76-\mathrm{I} .32)$ & 46.6 & $0.84(0.67-1.05)$ \\
\hline Heavy Chores & 47.7 & $1.00(0.83-1.20)$ & 44.0 & $0.54(0.33-0.90)$ & 55.8 & $1.25(0.96-1.63)$ & 42.9 & $1.01(0.81-1.26)$ \\
\hline Grocery Shopping & 25.9 & $0.92(0.74-1.14)$ & 47.2 & $1.67(0.99-2.83)$ & 30.7 & $1.02(0.76-1.37)$ & 19.4 & $0.84(0.64-1.09)$ \\
\hline Housework & 21.7 & $\mathrm{I} .02(0.82-1.27)$ & 39.8 & $1.75(1.03-2.96)$ & 18.5 & $0.66(0.47-0.91)$ & 20.9 & I.32 (I.02-I.72) \\
\hline Meal Preparation & 11.7 & $0.93(0.7|-| .23)$ & 23.0 & $\mathrm{I} .44(0.79-2.62)$ & 15.8 & $1.29(0.90-1.85)$ & 7.3 & $0.67(0.45-0.98)$ \\
\hline Personal Finances & 10.5 & I.22 (0.90-I.65) & 24.2 & $2.13(1.16-3.91)$ & 13.9 & $1.49(1.01-2.20)$ & 6.2 & $0.77(0.51-1.17)$ \\
\hline Personal Care & 4.5 & $0.80(0.52-1.21)$ & - & $\mathrm{I} .57(0.72-3.4 \mathrm{I})$ & 4.9 & $0.83(0.46-1.48)$ & 3.0 & $0.71(0.39-1.26)$ \\
\hline Moving Around Residence & 3.6 & $1.39(0.86-2.27)$ & - & $0.98(0.32-2.97)$ & - & $0.72(0.33-1.54)$ & 4.1 & $2.17(1.27-3.70)$ \\
\hline
\end{tabular}

SD-HA = Seeing Disabled, Hearing Able; HD-SA = Hearing Disabled, Seeing Able; SD-HD = Seeing Disabled, Hearing Disabled; SD and/or HD $($ Total $)=$ Seeing Disabled and/or Hearing Disabled (Total) $* \mathrm{n}=$ Weighted sample size ** Cell entries denoted by "-" are based on an unweighted $\mathrm{n}$ of less than 15 and have been suppressed due to the instability of the estimate. $\dagger$ Adjusted for all demographic variables, including Regions of Canada. Referent for the odds ratios compares respondents in each of the sensory disability categories (e.g. SD-HA) with all other persons in the HALS who were classified as disabled.

Table 4: Associations Between Sensory Disabilities and Assistance Needed with Instrumental Activities of Daily Living (IADL) Among Disabled Females 65 Years and Older, 199 I Health and Activity Limitation Survey $(n=687,508) *$

\begin{tabular}{|c|c|c|c|c|c|c|c|c|}
\hline \multirow[t]{2}{*}{ IADL Restriction } & \multicolumn{2}{|c|}{ SD and/or HD (Total) } & \multicolumn{2}{|c|}{ SD-HD } & \multicolumn{2}{|c|}{ SD-HA } & \multicolumn{2}{|c|}{ HD-SA } \\
\hline & $\%$ & Adj OR** (95\% Cl) & $\%$ & Adj OR** (95\% Cl) & $\%$ & Adj OR** $(95 \% \mathrm{Cl})$ & $\%$ & Adj OR** $(95 \% \mathrm{Cl})$ \\
\hline Any Activity & 68.7 & $0.73(0.57-0.93)$ & 80.0 & $1.26(0.84-1.88)$ & 73.0 & $1.20(0.88-1.64)$ & 61.3 & $0.64(0.50-0.82)$ \\
\hline Heavy Chores & 53.4 & $0.82(0.66-1.02)$ & 58.5 & $1.19(0.86-1.64)$ & 50.8 & $0.85(0.65-1.11)$ & 53.0 & $0.86(0.69-1.08)$ \\
\hline Grocery Shopping & 38.5 & $0.95(0.75-1.20)$ & 50.9 & $1.15(0.83-1.59)$ & 39.6 & $1.00(0.74-1.34)$ & 32.6 & $1.02(0.79-1.30)$ \\
\hline Housework & 36.6 & $0.89(0.70-1.13)$ & 51.5 & $1.32(0.95-1.82)$ & 33.2 & $0.70(0.5 \mathrm{I}-0.94)$ & 32.5 & $1.02(0.79-|.3|)$ \\
\hline Meal Preparation & 17.2 & $0.72(0.55-0.96)$ & 29.8 & $1.47(1.02-2.10)$ & 14.2 & $0.68(0.46-0.99)$ & 13.7 & $0.74(0.54-1.02)$ \\
\hline Personal Finances & 22.2 & $0.93(0.72-1.22)$ & 30.1 & $1.19(0.85-1.68)$ & 18.1 & $0.69(0.49-0.98)$ & 21.5 & $1.12(0.86-1.48)$ \\
\hline Personal Care & 14.3 & $1.26(0.89-1.79)$ & 26.6 & $1.84(1.26-2.69)$ & 16.2 & $1.21(0.82-1.79)$ & 8.1 & $0.66(0.45-0.98)$ \\
\hline Moving Around Residence & 8.0 & $0.94(0.62-1.43)$ & 10.3 & $\mathrm{I} .03(0.62-1.70)$ & 6.2 & $0.78(0.45-1.33)$ & 7.8 & $1.30(0.85-1.99)$ \\
\hline
\end{tabular}

Note: SD-HA = Seeing Disabled, Hearing Able; HD-SA = Hearing Disabled, Seeing Able; SD-HD = Seeing Disabled, Hearing Disabled; SD and/or $\mathrm{HD}($ Total $)=$ Seeing Disabled and/or Hearing Disabled $* n=$ Weighted sample size ** Adjusted for all demographic variables, including Regions of Canada. Referent for the odds ratios compares respondents in each of the sensory disability categories (e.g. SD-HA) with all other persons in the HALS who were classified as disabled.

nearly all IADLs than males in the same age group. More than two-third $(68.7 \%)$ of senior females and over onehalf $(56.9 \%)$ of senior males with a SD and/or HD indicated that they received assistance in performing at least one IADL. Among 55-64 year olds, 54.1\% of females with a SD and/or HD indicated they had at least one IADL restriction compared with $32.3 \%$ of males. The most common activities causing IADL restrictions among all older adults with a SD and/or HD were heavy chores $(26.3 \%$ to $53.4 \%)$, followed by grocery shopping ( $10.6 \%$ to $38.5 \%)$ and housework ( $10.1 \%$ to $36.6 \%)$. Activities causing relatively fewer restrictions among respondents with a SD and/or HD were moving around the residence $(2.2 \%$ to $8.0 \%)$, personal care ( $4.4 \%$ to $14.3 \%)$, and meal prepara- tion $(6.7 \%$ to $17.2 \%)$. Senior males with SD and/or HD were less likely to report restrictions with meal preparation compared with all other disabled respondents $(\mathrm{OR}=$ 0.61 ; 95\%CI: $0.42-0.87$ ). However, 55 to 64 year old males were more likely to report IADL restrictions related to their own personal care $(\mathrm{OR}=1.50 ; 95 \% \mathrm{CI}$ : $1.05-$ 2.15).

With regard to the three sensory disability classifications, individuals with both seeing and hearing disabilities (SDHD) reported having the most IADL restrictions, followed by individuals with only a seeing disability (SD-HA) and individuals with only a hearing disability (HD-SA). For example, $80 \%$ of senior females with SD-HD reported 
Table 5: Associations Between Sensory Disabilities and Assistance Needed with Instrumental Activities of Daily Living (IADL) Among Disabled Males 55-64 Years, 199 I Health and Activity Limitation Survey n = 267,9 18)*

\begin{tabular}{|c|c|c|c|c|c|c|c|c|}
\hline \multirow[t]{2}{*}{ IADL Restriction** } & \multicolumn{2}{|c|}{ SD and/or HD (Total) } & \multicolumn{2}{|c|}{ SD-HD } & \multicolumn{2}{|c|}{ SD-HA } & \multicolumn{2}{|c|}{ HD-SA } \\
\hline & $\%$ & Adj OR† $(95 \% \mathrm{Cl})$ & $\%$ & Adj OR† $(95 \% \mathrm{Cl})$ & $\%$ & Adj OR† $(95 \% \mathrm{Cl})$ & $\%$ & Adj OR† $(95 \% \mathrm{Cl})$ \\
\hline Any Activity & 32.2 & $0.81(0.67-0.98)$ & 59.7 & $2.03(1.20-3.43)$ & 48.9 & $1.27(0.87-1.83)$ & 28.0 & $0.72(0.59-0.88)$ \\
\hline Heavy Chores & 26.3 & $0.77(0.63-0.92)$ & 39.5 & $1.18(0.7 \mathrm{I}-1.96)$ & 38.6 & $1.12(0.77-1.63)$ & 23.7 & $0.74(0.6 \mathrm{I}-0.9 \mathrm{I})$ \\
\hline Grocery Shopping & 10.6 & $0.84(0.64-1.10)$ & 35.1 & $2.75(1.59-4.75)$ & 25.1 & $1.70(1.08-2.66)$ & 6.9 & $0.54(0.40-0.73)$ \\
\hline Housework & 10.1 & $0.79(0.6 \mathrm{I}-1.04)$ & 33.0 & $2.41(1.38-4.20)$ & 18.0 & $1.18(0.72-1.94)$ & 7.4 & $0.64(0.48-0.87)$ \\
\hline Meal Preparation & 6.7 & $0.89(0.64-1.24)$ & 24.5 & $3.19(1.73-5.88)$ & 16.8 & $1.67(0.98-2.82)$ & 4.1 & $0.5 \mathrm{I}(0.35-0.75)$ \\
\hline Personal Finances & 7.0 & $1.12(0.81-1.57)$ & 24.3 & $3.14(1.7 \mid-5.77)$ & 14.7 & $1.70(0.98-2.96)$ & 4.7 & $0.73(0.50-1.05)$ \\
\hline Personal Care & 6.5 & $1.50(1.05-2.15)$ & - & $0.29(0.08-1.11)$ & 8.2 & $1.51(0.76-3.01)$ & 6.5 & $1.75(I .22-2.5 I)$ \\
\hline Moving Around Residence & 2.2 & $1.30(0.69-2.42)$ & - & $0.47(0.08-2.85)$ & - & $2.03(0.7 \mathrm{I}-5.77)$ & 2.0 & $1.30(0.69-2.45)$ \\
\hline
\end{tabular}

Note: SD-HA = Seeing Disabled, Hearing Able; HD-SA = Hearing Disabled, Seeing Able; SD-HD = Seeing Disabled, Hearing Disabled; SD and/or HD $($ Total $)=$ Seeing Disabled and/or Hearing Disabled * $n=$ Weighted sample size ** Cell entries denoted by "-" are based on an unweighted $n$ of less than 15 and have been suppressed due to the instability of the estimate. $\dagger$ Adjusted for all demographic variables, including Regions of Canada. Referent for the odds ratios compares respondents in each of the sensory disability categories (e.g. SD-HA) with all other persons in the HALS who were classified as disabled.

Table 6: Associations Between Sensory Disabilities and Assistance Needed with Instrumental Activities of Daily Living (IADL) Among Disabled Males 65 Years and Older, 199 I Health and Activity Limitation Survey $(n=522,603) *$

\begin{tabular}{|c|c|c|c|c|c|c|c|c|}
\hline \multirow[t]{2}{*}{ IADL Restriction** } & \multicolumn{2}{|c|}{ SD and/or HD (Total) } & \multicolumn{2}{|c|}{ SD-HD } & \multicolumn{2}{|c|}{ SD-HA } & \multicolumn{2}{|c|}{ HD-SA } \\
\hline & $\%$ & Adj OR† $(95 \% \mathrm{Cl})$ & $\%$ & Adj OR† $(95 \% \mathrm{Cl})$ & $\%$ & Adj OR† $(95 \% \mathrm{Cl})$ & $\%$ & Adj ORt $(95 \% \mathrm{Cl})$ \\
\hline Any Activity & 56.9 & $1.10(0.83-1.45)$ & 68.5 & $1.42(0.93-2.17)$ & 63.9 & I.3I (0.85-2.0I) & 51.4 & $0.93(0.70-1.24)$ \\
\hline Heavy Chores & 49.5 & $1.38(1.06-1.81)$ & 52.3 & $0.96(0.65-1.4 I)$ & 57.5 & $1.59(1.06-2.40)$ & 46.7 & $1.20(0.91-1.58)$ \\
\hline Grocery Shopping & 19.3 & $0.81(0.56-1.17)$ & 30.2 & $1.33(0.84-2.08)$ & 26.4 & $1.65(0.99-2.76)$ & 14.0 & $0.62(0.42-0.89)$ \\
\hline Housework & 21.3 & $0.83(0.60-1.16)$ & 29.5 & $1.08(0.70-1.65)$ & 34.3 & $1.87(1.20-2.91)$ & 15.3 & $0.58(0.4 \mathrm{I}-0.8 \mathrm{I})$ \\
\hline Meal Preparation & 15.1 & $0.61(0.42-0.87)$ & 26.1 & $1.39(0.88-2.20)$ & 20.9 & $1.18(0.71-1.95)$ & 10.0 & $0.43(0.29-0.63)$ \\
\hline Personal Finances & 20.0 & $1.26(0.88-1.80)$ & 32.7 & $1.76(1.15-2.70)$ & 23.4 & $1.21(0.74-1.98)$ & 15.1 & $0.79(0.55-1.13)$ \\
\hline Personal Care & 10.2 & $0.85(0.54-1.36)$ & 19.1 & $1.52(0.88-2.61)$ & 13.4 & $1.64(0.87-3.09)$ & 6.6 & $0.58(0.36-0.95)$ \\
\hline Moving Around Residence & 5.2 & $0.89(0.47-1.67)$ & 12.0 & $1.84(0.91-3.70)$ & - & $0.32(0.08-1.25)$ & 3.9 & $0.89(0.47-1.70)$ \\
\hline
\end{tabular}

Note: SD-HA = Seeing Disabled, Hearing Able; HD-SA = Hearing Disabled, Seeing Able; SD-HD = Seeing Disabled, Hearing Disabled; SD and/or HD $($ Total $)=$ Seeing Disabled and/or Hearing Disabled * $n=$ Weighted sample size ** Cell entries denoted by "-" are based on an unweighted $\mathrm{n}$ of less than 15 and have been suppressed due to the instability of the estimate. $\dagger$ Adjusted for all demographic variables, including Regions of Canada. Referent for the odds ratios compares respondents in each of the sensory disability categories (e.g. SD-HA) with all other persons in the HALS who were classified as disabled.

IADL restrictions for any activity compared with $73.0 \%$ with SD-HA, and $61.3 \%$ with HD-SA (Table 4). Similarly, $68.5 \%$ of senior males with SD-HD indicated IADL restrictions for any activity compared with $63.9 \%$ of males with SD-HA and 51.4\% with HD-SA (Table 6). Heavy chores, grocery shopping and housework were generally reported as the main activities causing IADL restriction in each of the sensory disability classifications. Senior males with SD-HD and HD-SA, however, also reported personal finances as one of their main IADL restriction. Approximately one third $(32.7 \%)$ of senior males with SD-HD and $15.1 \%$ of senior males with HD-SA indicated that they required assistance with personal finances.
Individuals with SD-HD were generally at higher risk of reporting an IADL restriction compared with other respondents with disabilities. For instance, males aged 55-64 years old with SD-HD were more than twice as likely to require assistance with grocery shopping ( $\mathrm{OR}=$ 2.75, 95\%CI: 1.59 to 4.74$)$, housework $(\mathrm{OR}=2.41$, 95\%CI: 1.38 to 4.20$)$, meal preparations $(\mathrm{OR}=3.19$, $95 \% \mathrm{CI}: 1.73$ to 5.88$)$, and personal finances $(\mathrm{OR}=3.14$, 95\%CI: 1.71 to 5.77 ) than all other disabled respondents (Table 4). Individuals with HD-SA, however, were generally at lower risk of reporting IADL restrictions. For instance, senior males with HD-SA were less likely to require assistance with grocery shopping $(\mathrm{OR}=0.62$, 
Table 7: Association between Severity of Sensory Disability and Functional Independence, 199 I Health and Activity Limitation Survey

\begin{tabular}{|c|c|c|c|}
\hline Degree of Sensory Severity & IADL Restriction & Decision Making & Emotional Well-being \\
\hline \multicolumn{4}{|l|}{ SD and/or HD } \\
\hline Mild & Referent & Referent & Referent \\
\hline Moderate & $0.98(0.82-1.18)$ & $0.86(0.63-1.18)$ & $0.94(0.74-1.18)$ \\
\hline Severe & $1.33(1.07-1.65)$ & $0.54(0.40-0.74)$ & $0.70(0.54-0.89)$ \\
\hline \multicolumn{4}{|l|}{ SD-HD } \\
\hline Mild & Referent & Referent & Referent \\
\hline Moderate & $0.77(0.38-1.55)$ & $0.39(0.13-1.22)$ & $0.87(0.44-1.72)$ \\
\hline Severe & $\mathrm{I} .03(0.52-2.03)$ & $0.22(0.07-0.63)$ & $0.81(0.43-1.54)$ \\
\hline \multicolumn{4}{|l|}{ SD-HA } \\
\hline Mild & Referent & Referent & Referent \\
\hline Moderate & I.I $6(0.78-1.70)$ & $0.65(0.37-1.14)$ & $1.19(0.76-1.86)$ \\
\hline Severe & $3.81(2.19-6.63)$ & $0.99(0.49-1.97)$ & $0.85(0.52-1.39)$ \\
\hline \multicolumn{4}{|l|}{ HD-SA } \\
\hline Mild & Referent & Referent & Referent \\
\hline Moderate & $0.89(0.7 I-1.1 I)$ & $0.87(0.58-1.3 \mid)$ & $0.74(0.53-1.01)$ \\
\hline Severe & $0.82(0.60-1.12)$ & $0.54(0.34-0.87)$ & $0.77(0.50-1.18)$ \\
\hline
\end{tabular}

Note: SD-HA = Seeing Disabled, Hearing Able; HD-SA = Hearing Disabled, Seeing Able; SD-HD = Seeing Disabled, Hearing Disabled; SD and/or HD $($ Total $)=$ Seeing Disabled and/or Hearing Disabled Odds ratios adjusted for all demographic variables, including Regions of Canada. Referent for the odds ratios compares respondents in each of the sensory disability categories (e.g. SD-HA) with all other persons in the HALS who were classified as disabled.

95\%CI: 0.42 to 0.89$)$, housework (OR $=0.58,95 \% \mathrm{CI}$ : 0.41 to 0.81 ), meal preparation (OR-0.43,95\%CI: 0.29 to 0.63 ), and personal care ( $\mathrm{OR}=0.58,95 \% \mathrm{CI}$ : 0.36 to 0.95 ) than all other disabled respondents (Table 6).

The pattern observed for individuals with SD-HA was less consistent. Females aged 55 to 64 years old with SD-HA were less likely to need assistance for housework (OR = 0.66, 95\%CI: 0.47-0.91) than all other disabled individuals. However, senior men with SD-HA were more likely to require assistance with heavy chores $(\mathrm{OR}=1.59$, 95\%CI: 1.06 to 2.40$)$ and housework $(\mathrm{OR}=1.87,95 \% \mathrm{CI}$ : 1.20 to 2.91 ).

\section{Relationship between severity of sensory disability and functional independence}

The association between severity of sensory disability and the three measures of functional independence are shown in Table 7. The findings showed a general trend of increasing OR for IADL restriction, and decreasing OR for decision-making control and emotional well-being with greater severity of disability in each classification. For example, respondents with severe SD-HA were almost four times more likely than those with a mild severity of SD-HA to report IADL restrictions $(\mathrm{OR}=3.81,95 \% \mathrm{CI}$ : 2.19-6.63). As well, respondents with severe SD and/or HD were less likely to have decision-making control (OR $=0.54,95 \% \mathrm{CI}: 0.40$ to 0.74$)$ and be happy with their lives (OR $=0.70,95 \% \mathrm{CI}: 0.54$ to 0.89 ) compared with individuals with mild sensory severity.

\section{Discussion}

Vision and hearing impairments are an important source of concern among adults aged 55 years and older in Canada [7]. Our findings showed more than $23 \%$ of Canadian seniors and more than $10 \%$ of 55-64 year olds reported a sensory disability that resulted from impairment lasting six months or more. These individuals reported restrictions in routine activities such as heavy chores, grocery shopping, housework, and personal finances. Furthermore, in each sensory classification, females in both age groups reported more IADL restrictions than their male counterparts. These findings supported previous research $[8,9]$ that showed a higher prevalence of vision impairment in women than men.

These results are disconcerting given that the proportion of older adults is increasing in Canada, and that seeing and hearing impairments are one of the most widespread sensory deficits associated with normal aging $[9,10]$. Our figures of sensory disabilities among older adults are likely to be population underestimations, particularly since they excluded institutionalised individuals, such as those in nursing homes. The rates of sensory impairments among nursing home residents have been estimated to be at least four times higher than for seniors living in the community $[11,12]$. Poor hearing has been correlated with greater subsequent risk of requiring nursing home care $[13,14]$.

Respondents with both seeing and hearing disabilities (SD-HD) reported the most restrictions in their ADL activ- 
ities, followed by SD-HA individuals and then HD-SA individuals. Older SD-HD adults were also more likely to require assistance with their daily activities than all other disabled respondents. It is not surprising that respondents with HD-SA were less likely to require assistance with IADL compared to other individuals with a disability. Our findings also showed that visual disabilities may be associated with more IADL restrictions than hearing disabilities since vision is generally more necessary than hearing in accomplishing important ADL activities, such as household chores or grocery shopping.

Our study also showed that individuals with severe sensory disabilities were more likely to have an IADL restriction and less likely to have decision-making control and be happy with their lives than individuals with mild sensory disabilities. Decrements in seeing and hearing impairment associated with IADL restrictions were supported by Dargent-Molina and colleagues [15]. They found that community-dwelling women aged 75 years and older with serious hearing difficulties were four times more likely to be physically dependent than respondents with less serious hearing difficulties. Moreover, elderly women with visual impairments, such as low visual acuity and low contrast sensitivity, were almost twice as likely to be physically disabled compared with women with good vision [15].

Our findings suggest the need to pay greater attention to visual and hearing impairments that can lead to disability among older adults. Unfortunately these impairments are often overlooked because older adults are likely to accept vision and hearing loss as inevitable consequences of normal aging. Furthermore, health care professionals have been shown to regard vision and hearing problems in the elderly as benign, and therefore not posing a risk to the elderly person's physical, emotional or social function [16] despite the existence of literature demonstrating that factors, such as reduced mobility and physical functioning $[17,18]$, reduced social activities and enjoyment in life $[10,19]$, and increased depressive symptoms and dependency $[15,20,21]$ can be associated with hearing impairment.

\section{Conclusions}

With the increasing need for and use of health care services due to an aging population, the major goal in public health and medicine is to keep elderly individuals living independently and to prevent institutionalisation. This will require good maintenance of functional health including physical, emotional, cognitive and social function. However, visual and hearing impairments are rarely the only the condition causing functional problems. Although our study suggests that small improvements in vision and hearing impairment may enhance physical and psychological functioning in older adults, future research will need to examine the influence of other concurrent health conditions on sensory disabilities. Furthermore, the cross-sectional nature of our study did not allow for making inferences about the causal nature of the associations. Although it is unlikely that physical disability would cause sensory disability, it is more likely that both sensory function and physical ability decrease with aging so that sensory impairment accompanies physical disability. The relationship between sensory impairments and IADL dependency is complex [22]. Therefore, future research will also need to focus on identifying the factors that will lead to better health and functional outcomes for the older individual.

\section{Competing interests}

None declared.

\section{List of abbreviations}

IADL - Instrumental activities of daily living

HALS - Health and Activities Limitations Survey

ADL - Activities of daily living

SD-HA - Seeing disabled but hearing abled

HD-SA - Hearing disabled but seeing abled

SD-HD - Seeing disabled and hearing disabled

SD and/or HD - Seeing disabled and/or hearing disabled (total)

OR - Odds ratio

CI - Confidence interval

\section{Authors' contributions}

PR carried out the conceptualization, design, analysis, and writing of the study and paper, MW participated in the analysis of the study and writing of the paper. HM participated in writing of the paper.

\section{Acknowledgments}

Dr. Raina holds a National Health Scholar Award from National Health Research and Development Program (NHRDP) and an Investigator Award from Canadian Institute of Health Research (CIHR) 2004-2009 and an Ontario Premier Excellence Award (PREA) in 2004. Funding for this project was provided by the SEDAP program of Social Sciences and Humanities Research Council. We would also like to acknowledge the contributions to the editorial content from Devon Christie and Roxanne Cheeseman.

\section{References}

I. Raina P, Wong M, Dukeshire S, Chambers LW, Lindsay J: Prevalence, risk factors and self-reported medical causes of seeing 
and hearing-related disabilities among older adults. Canadian Journal of Aging 2000, 19:260-278.

2. Statistics Canada: Users Guide: Health and Activity Limitation Survey. Ottawa, Statistics Canada 1987.

3. Raina P, Dukeshire S, Lindsay J, Chambers LW: Chronic conditions and disabilities among seniors: an analysis of populationbased health and activity limitation surveys. Ann Epidemiol 1998, 8:402-409.

4. Statistics Canada: Disability Score for the health and Activity Limitation Survey. Ottawa, Statistics Canada 1988.

5. Haan M, Kaplan GA, Camacho T: Poverty and health. Prospective evidence from the Alameda County Study. Am J Epidemiol 1987, I 25:989-998.

6. Jenkins CD, Tuthill RW, Tannenbaum SI, Kirby C: Social stressors and excess mortality from hypertensive diseases. J Human Stress 1979, 5:29-40

7. Raina P, Dukeshire S, Lindsay J, Chambers LW: Sensory Impairment among Canadians 55 Years Old and Older: An Analysis of 1986 and 1991 Health and activity limitation Survey. IESOP Research Paper No. 18. Hamilton, ON, McMaster University 1997.

8. Campbell VA, Crews JE, Moriarty DG, Zack MM, Blackman DK: Surveillance for sensory impairment, activity limitation, and health-related quality of life among older adults - United States, 1993-1997. MMWR CDC Surveill Summ 1999, 48: I3I-I56.

9. Wallhagen MI, Strawbridge WJ, Shema SJ, Kurata J, Kaplan GA: Comparative impact of hearing and vision impairment on subsequent functioning. J Am Geriatr Soc 200I, 49:1086-1092.

10. Weinstein BE, Ventry IM: Hearing impairment and social isolation in the elderly. J Speech Hear Res 1982, 25:593-599.

II. Tielsch JM, Javitt JC, Coleman A, Katz J, Sommer A: The prevalence of blindness and visual impairment among nursing home residents in Baltimore. N Engl J Med 1995, 332:1205-1209.

12. Marx MS, Werner P, Cohen-Mansfield J, Feldman R: The relationship between low vision and performance of activities of daily living in nursing home residents. J Am Geriatr Soc 1992, 40:1018-1020.

13. Osterweil D, Martin M, Syndulko K: Predictors of skilled nursing placement in a multilevel long-term-care facility. J Am Geriatr Soc 1995, 43:108-112.

14. Uhlmann RF, Larson EB, Koepsell TD: Hearing impairment and cognitive decline in senile dementia of the Alzheimer's type. J Am Geriatr Soc 1986, 34:207-210.

15. Dargent-Molina P, Hays M, Breart G: Sensory impairments and physical disability in aged women living at home. Int J Epidemiol 1996, 25:621-629.

16. Bess FH, Lichtenstein MJ, Logan SA, Burger MC, Nelson E: Hearing impairment as a determinant of function in the elderly. J $A m$ Geriatr Soc 1989, 37:123-128.

17. Salive ME, Guralnik J, Glynn RJ, Christen W, Wallace RB, Ostfeld AM: Association of visual impairment with mobility and physical function. J Am Geriatr Soc 1994, 42:287-292.

18. Branch LG, Horowitz A, Carr C: The implications for everyday life of incident self-reported visual decline among people over age 65 living in the community. Gerontologist 1989, 29:359-365.

19. Carabellese C, Appollonio I, Rozzini R, Bianchetti A, Frisoni GB, Frattola $L$, Trabucchi M: Sensory impairment and quality of life in a community elderly population. J Am Geriatr Soc 1993, $4 \mathrm{I}: 40 \mathrm{I}-407$.

20. Laforge R, Spector WD, Sternberg J: The relationship of vision and hearing impairment to one-year mortality and functional decline. Journal of Aging and Health 1992, 4: I26-I48.

21. Mulrow CD, Aguilar C, Endicott JE, Velez R, Tuley MR, Charlip WS, Hill JA: Association between hearing impairment and the quality of life of elderly individuals. J Am Geriatr Soc 1990, 38:45-50.

22. Keller BK, Morton JL, Thomas VS, Potter JF: The effect of visual and hearing impairments on functional status. J Am Geriatr Soc 1999, 47:1319-1325.

\section{Pre-publication history}

The pre-publication history for this paper can be accessed here: http://www.biomedcentral.com/1471-2318/4/3/prepub
Publish with Bio Med Central and every scientist can read your work free of charge

"BioMed Central will be the most significant development for disseminating the results of biomedical research in our lifetime. " Sir Paul Nurse, Cancer Research UK

Your research papers will be:

- available free of charge to the entire biomedical community

- peer reviewed and published immediately upon acceptance

- cited in PubMed and archived on PubMed Central

- yours - you keep the copyright

Submit your manuscript here:

http://www.biomedcentral.com/info/publishing_adv.asp
BiolMedcentral 